\title{
HIGHLIGHTS of HealthAchieve 2011
}

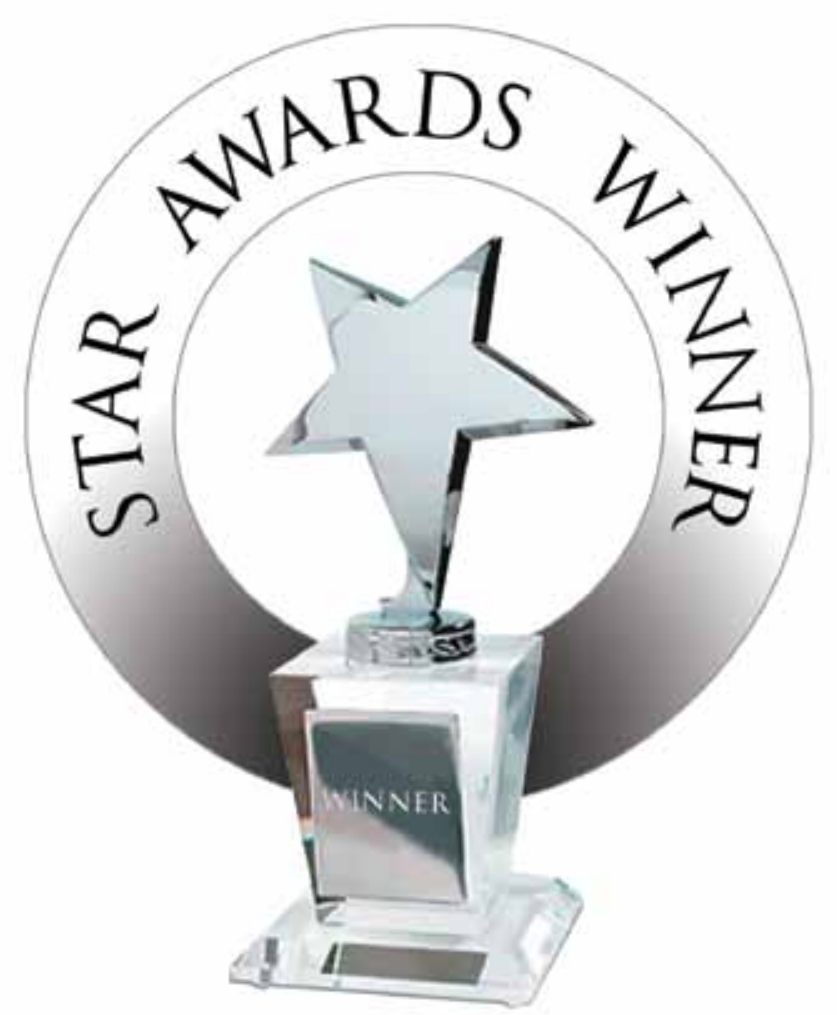

\section{OHA's HealthAchieve Honoured at Annual Canadian Event Industry Awards}

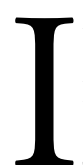

ts 2011 and the OHA was again recognized for its progressive annual conference and exhibition, HealthAchieve - one of the largest healthcare shows in North America.

On March 25, 2011, the association was presented with the prestigious 'Best Event Produced by an Association' award.

The "Art of the Show Competition" recognizes excellence in show promotion. Submissions come from around the world. Winning entries are featured at Expo!
Expo! IAEE's Annual Meeting \& Exhibition held the following December 2011 in Las Vegas, NV. In 2011, three first place awards were granted to the OHA.

This looks good on everybody: the association and its agencies, corporate sponsors, presenters and the many thousands who walked the distance to explore new ideas, products and solutions, networked their way to better healthcare and learned from to some of the most impressive achievers in the world.

Congrats to everyone! 


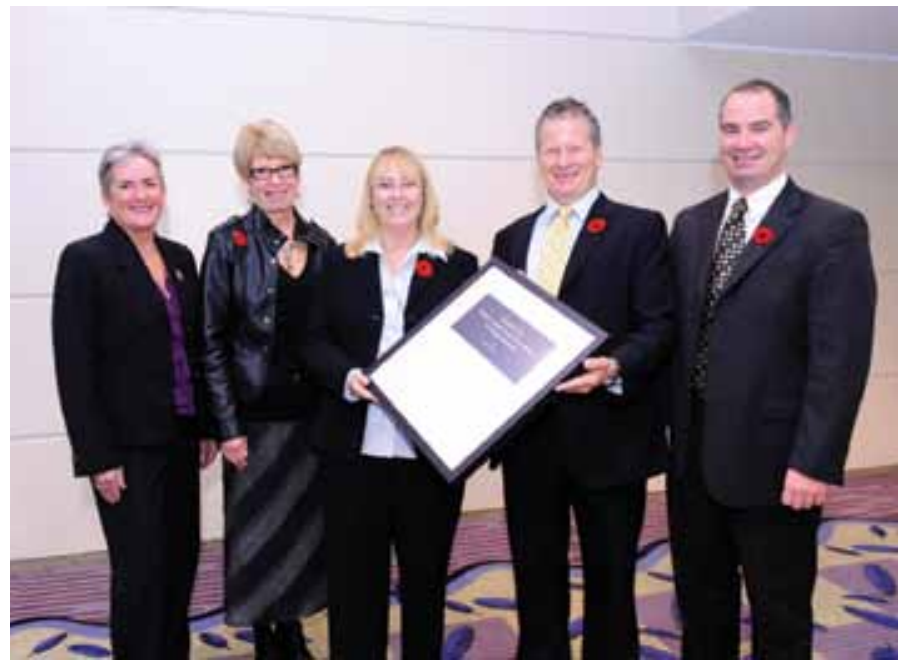

\section{The Margret Comack Award of Excellence in Nursing Leadership}

The winner is Dr. Sue Matthews.

Left to Right: Lynn Nagle, Margret Comack, Dr. Sue Matthews, Paul Bradley, Steve DeNoble.

Sponsored by formentaten $\quad \begin{gathered}\text { Nursing } \\ \text { Leadership }\end{gathered}$

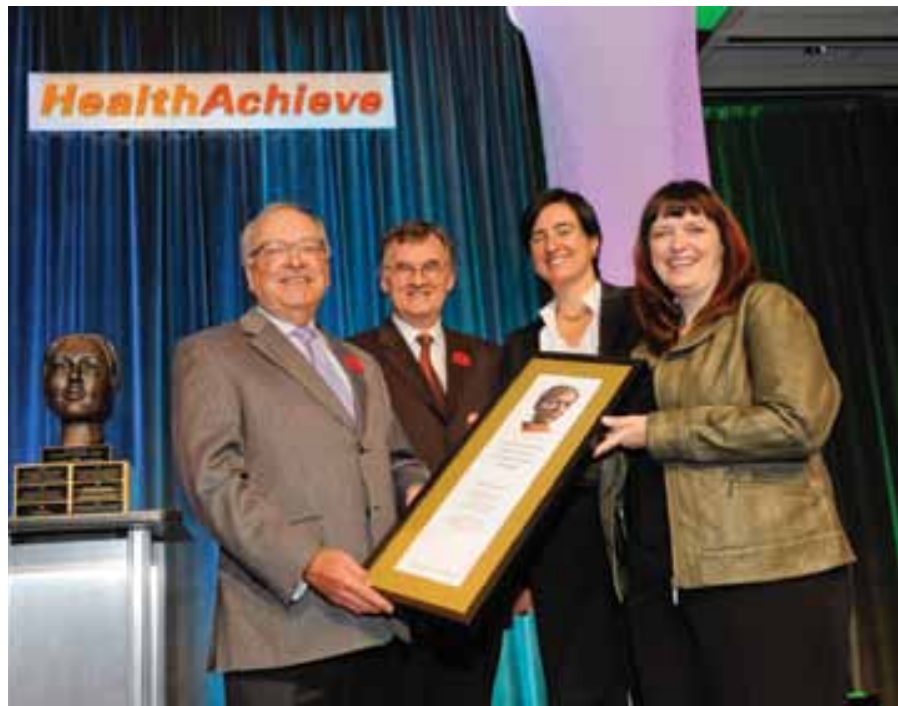

\section{The Ted Freedman Award}

The winner is: Joint submission from Canadian Patient Safety Institute and Canadian Health Services Research Foundation. In recognition of Workshops for Effective Governance for Quality and Patient Safety.

Left to Right: Ted Freedman; Anton Hart, Longwoods Publishing Corporation; Maria Judd, Canadian Health Services Research Foundation; Abigail Hain, Canadian Patient Safety Institute.

Sponsored by Longwoods.com HealthAchieve

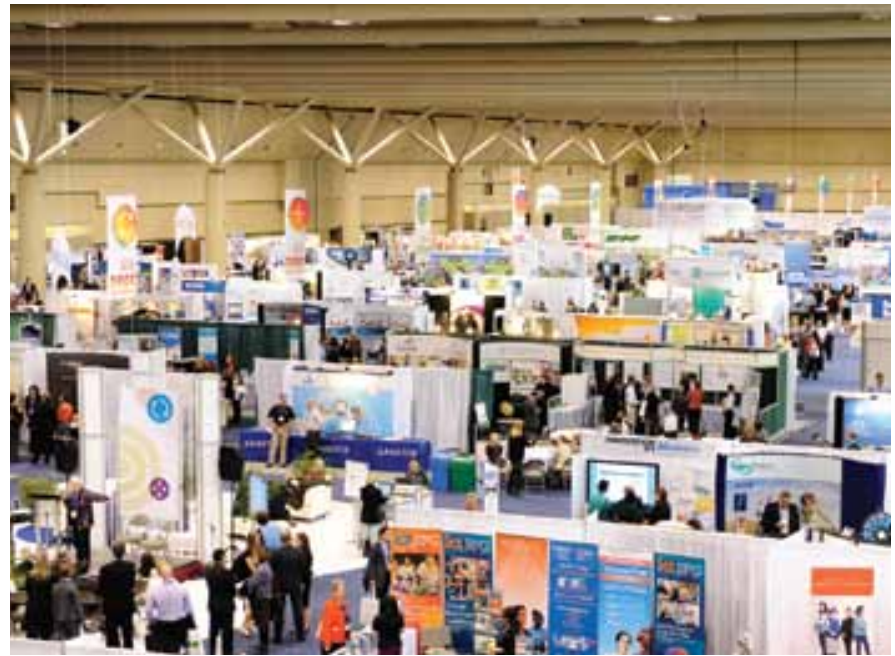

\section{Exhibitor's Awards}

1. Best New Exhibitor - ABS System Consultants

2. Best Single - Keebee Play

3. Best Double - HealthForceOntario Marketing and Recruitment Agency

4. Best Multiple - Stryker

5. Best of Show - Healthcare of Ontario Pension Plan (HOOPP)

6. People's Choice - Centric Health Corporation 

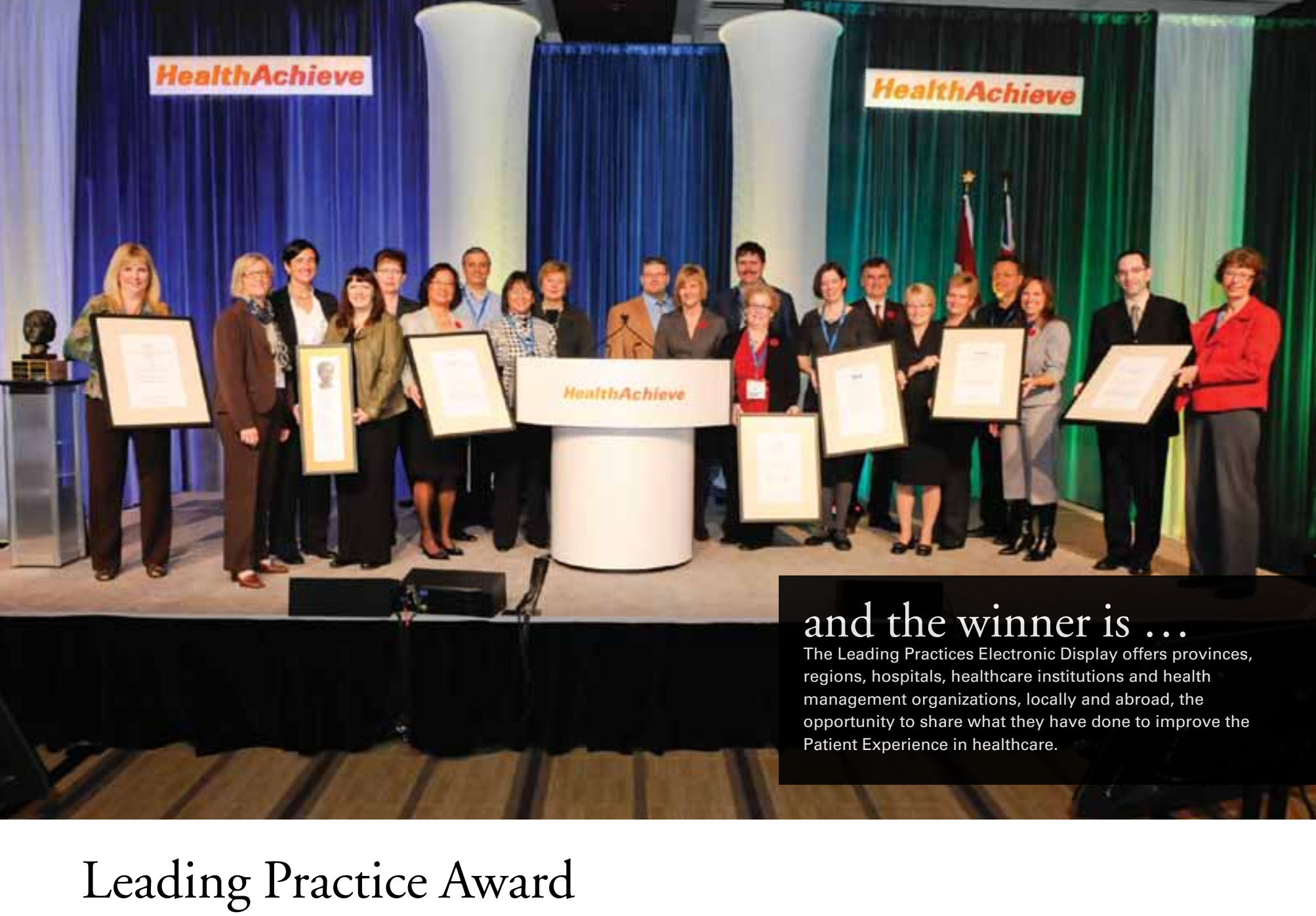

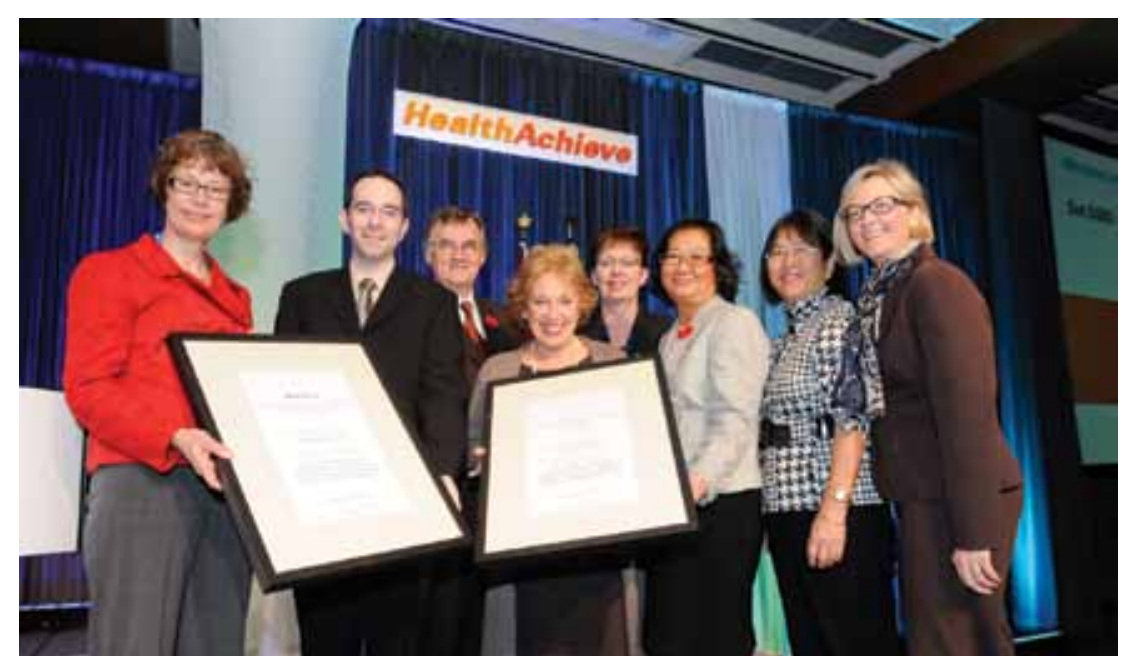

The 3M Health Care Leading Practice Award Winners in Patient Safety \& Quality

Overall winner Trillium Health Centre - A Nurse-Led Clinical Protocol: Significant Reductions in Unnecessary Urinary Catheters and Overall Catheter Prevalence at Trillium Health Centre.

From left: Laura Robbs, Trillium Health Center; Dr. Amir Ginzburg, Trillium Health Center; Anton Hart, Longwoods Publishing Corporation; Janet M. Davidson, Trillium Health Center; Morag McLean, Trillium Health Centre and The Credit Valley Hospital; May Chang, Trillium Health Centre; Patti Cochrane, Trillium Health Centre; and Susan Bisaillon, Trillium Health Centre.

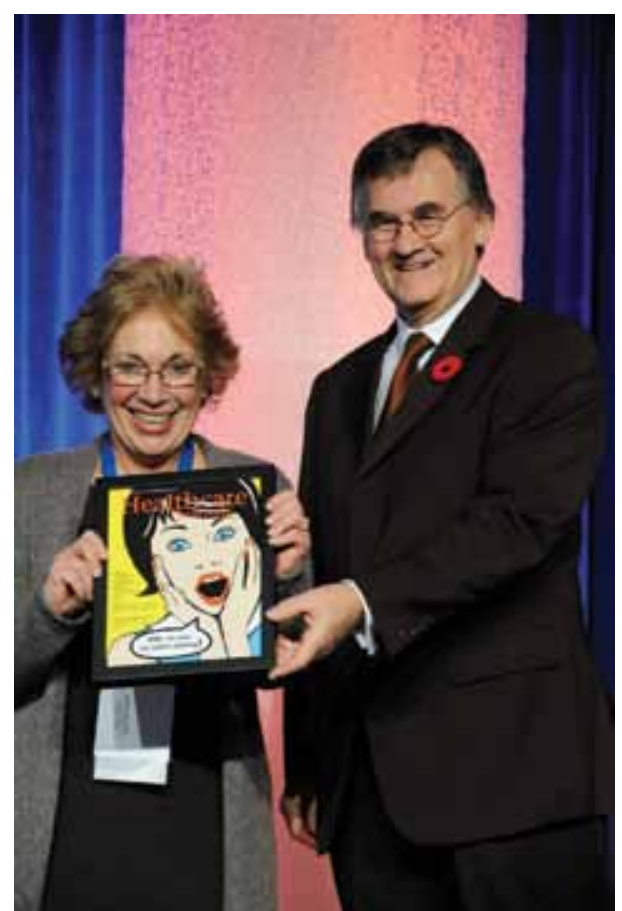

Janet M. Davidson, President and CEO, Trillium Health Center reviewing the "Best of the Leading Practices" certificates from Anton Hart, CEO, Longwoods Publishing Corporation. 


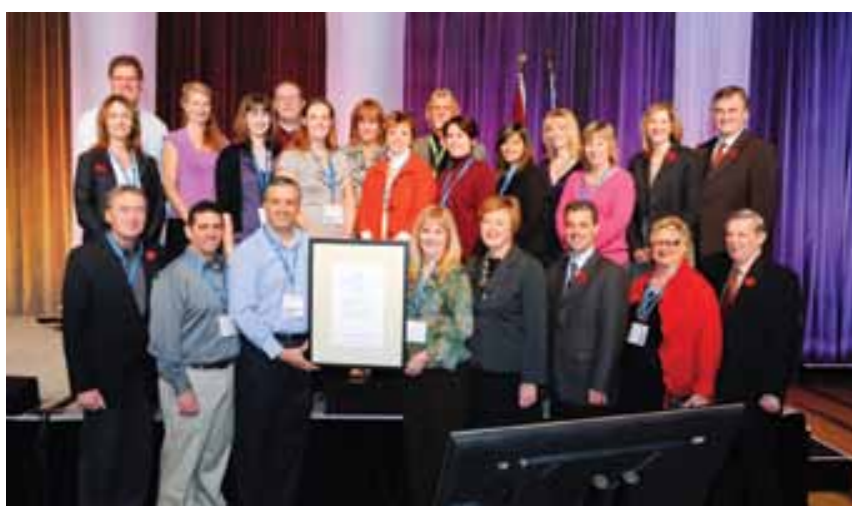

The Strata Health Leading Practice Award Winners in Access to Care -

Windsor Regional Hospital - Polarizing MRI Wait Times

Front Row: Bob Renaud, Cary Bedard, Ralph Nicoletti and Colleen Nelson, Kris Bailey, Jeff Booth, Patty Kerr, Wilf Innerd.

Back Row: Kim Van Vliet, JP Brescacin, Sally Bennett, Gillian Koolen, Matthew Grayson, Sandra Shearme, Joanne Barbera, Linda Morrow, Nick Dzudz, Jen Cameron, Neelu Sehgal, Katharina Strong, Kathy Lyons, Daniela Lockhard, Anton Hart.

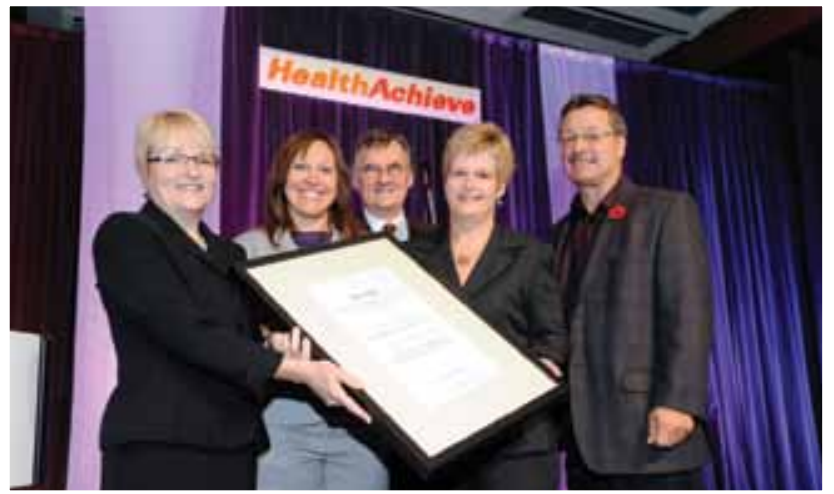

The Cerner Leading Practice Winners in Governance \& Integration St. Joseph's Care Group (Thunder Bay) - Leading Change Collaboratively for Enhanced Interprofessional Practice

Penny Anguish, Michelle Addison, Anton Hart, Tracy Buckler, Doug Demeo

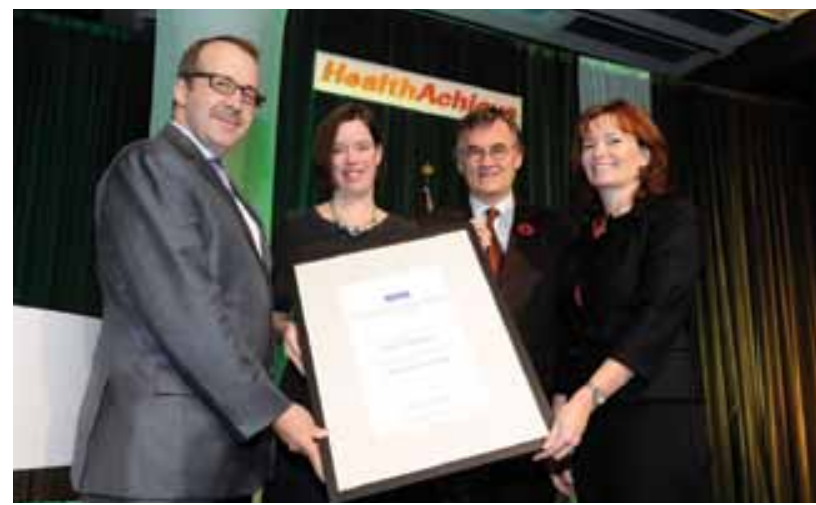

The KPMG Leading Practice Award Winners in Patient Experience Hamilton Health Sciences - Patient Experience Mapping

Dylan Hard, KPMG; Emily Christoffersen, Anton Hart, Georgina Black, KPMG

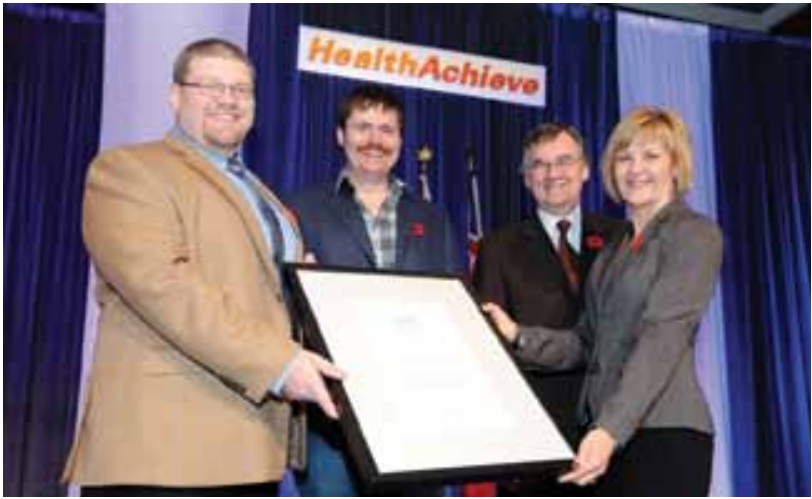

The IBM Leading Practice Winners in Innovation North Bay Regional Health Centre - Emergency Department Physician Speed Sensitive Scheduling

Les Blackwell, Dr. Scott Daley, Anton Hart, Nancy Jacko

\section{Thank you to our sponsors}

\section{M Health Care
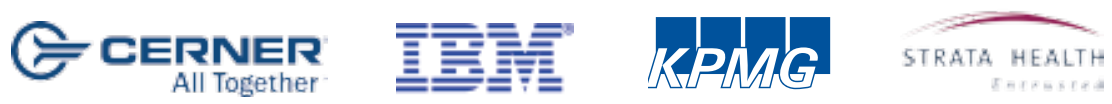

\section{Thank you}

Special thanks to the adjudicators of the Leading Practice Displays:

Rob Crawford, Crawford and Associates and Shirley Bryant, Toronto Central LIHN

with Dianne Foster-Kent, Editorial Director at Longwoods Publishing. 
